\title{
Erratum to: Treatment of Pancreatic Diseases
}

\author{
Milan Kujundžić, Željko Čabrijan, and Tomislav Bokun
}

\section{Erratum to: \\ Chapter 19 in: M. Duvnjak, L. Smirčić-Duvnjak (eds.), Gastrointestinal Complications of Diabetes, Clinical Gastroenterology, https://doi.org/10.1007/978-3-319-75856-5}

In chapter 19, co-author's name is missing an accent mark on the first letter. Zeljko Čabrijan should be written as Željko Čabrijan.

This has been updated in ToC, LoC and chapter 19 .

The updated online version of this chapter can be found at 10.1007/978-3-319-75856-5_19

M. Kujundžić $(\bowtie) \cdot$ Ž. Čabrijan · T. Bokun

Department of Gastroenterology, Hepatology and Clinical Nutrition,

University Hospital Dubrava, Zagreb, Croatia

University of Zagreb School of Medicine, Zagreb, Croatia

e-mail: milankdz@kbd.hr 